\title{
Contrast-enhanced ultrasonography: is it an ideal tool for hepatocellular carcinoma surveillance?
}

\author{
Hitoshi Maruyama, Shuichiro Shiina \\ Department of Gastroenterology, Juntendo University, Hongo, Bunkyo-ku, Tokyo, Japan \\ Correspondence to: Dr Hitoshi Maruyama. Department of Gastroenterology, Juntendo University, 2-1-1, Hongo, Bunkyo-ku, Tokyo, 113-8421, Japan. \\ Email: h.maruyama.tw@juntendo.ac.jp. \\ Comment on: Park JH, Park MS, Lee SJ, Jeong WK, Lee JY, Park MJ, Lee SS, Han K, Nam CM, Park SH, Lee KH. Contrast-enhanced US with \\ Perfluorobutane for Hepatocellular Carcinoma Surveillance: A Multicenter Diagnostic Trial (SCAN). Radiology 2019;292:638-46.
}

Submitted Aug 27, 2019. Accepted for publication Sep 03, 2019.

doi: 10.21037/qims.2019.08.20

View this article at: http://dx.doi.org/10.21037/qims.2019.08.20

Hepatocellular carcinoma (HCC) is increasing worldwide and is a common cancer in both males and females (1). It is also the major leading cause of cancer-related death, with an incidence-to-mortality ratio close to 1.0 (2).

Unlike the other malignancies, HCC develops in patients with chronic liver disease typified with advanced fibrosis. Despite the recent transition of the patient population by the control of viruses with oral medications, cirrhosis patients with chronic hepatitis B virus (HBV) or hepatitis $\mathrm{C}$ virus (HCV) infection remain the major risk factors. Those with alcohol abuse, primary biliary cholangitis, nonalcoholic steatohepatitis (NASH), autoimmune hepatitis, or other etiologies also have a risk for developing HCC. Furthermore, Asian males $\geq 40$ years, Asian females $\geq 50$ years, family history of HCC, and Africans $\geq 20$ years are considered high-risk groups in patients with chronic HBV infection even without cirrhosis (3). The ideal surveillance of HCC can be achieved based on the recognition of these risk factors.

The purpose of HCC surveillance is to recognize early stage lesions that are candidates for curative treatment, such as local ablation or surgical resection. HCC surveillance is also expected to contribute to the improvement of their survival. Regarding the surveillance interval, a Chinese study conducted in 18,816 patients with $\mathrm{HBV}$ infection or a history of chronic hepatitis reported that biannual screening reduced HCC mortality by $37 \%$ (4). A recent multi-center cohort study addressed the association of compliance with HCC surveillance guidelines (fewer than 7 months between image evaluations) in the early diagnosis of HCC, allocation of curative treatment, and longer lead time adjusted overall survival of patients with $\mathrm{HCV}$ - or HBV-associated compensated cirrhosis and a diagnosis of HCC (5). It follows the evidence available of a survival benefit with 6-months HCC surveillance. In addition, Trinchet et al. demonstrated that ultrasound (US) surveillance every 3 months detects more small focal lesions than US every 6 months but does not improve the detection of small HCCs (6). These data strongly support the validity of HCC surveillance under a 6-month time frame, which is also recommended by international guidelines (7-9). Surveillance program based on personalized medicine following further stratification of risk assessment is the challenge for the future.

Combinations of radiographic tests [US, computed tomography (CT) or magnetic resonance imaging (MRI)] and serologic tests (alpha-fetoprotein, alpha-fetoprotein L3, and PIVKAII) are common surveillance strategies for HCC. Due to the possible adverse events caused by the CT/MRI contrast materials, that is, allergy and nephrotoxic potential, US is often used in daily medical care with an established fact of "safety is a top priority". Because of the availability of microbubble-based materials, contrast-enhanced US (CEUS) has become popular with the advantages of less invasiveness, real-time observation, and fewer side effects (10). Following the first-generation contrast agent 
Levovist, several kinds of second-generation agents have been introduced with the improved stability of microbubbles and the efficiency of contrast effects, i.e., SonoVue, Definity, and Sonazoid (11). Because of its unique property of microbubble accumulation in the reticuloendothelial system, so-called post-vascular phase or Kupffer phase, Sonazoid is frequently used for the detailed assessment of focal liver lesions. Investigators have shown the benefits of CEUS with Sonazoid for the detection of HCCs that could not be recognized by B-mode US, the improvement of the conspicuous border line of hepatic lesions, the assessment of tumor vascularity, tumor characterization, the evaluation of HCC cellular differentiation, and various therapeutic support methods (10).

Against these backgrounds, Park et al. reported interesting data about CEUS with Sonazoid in HCC surveillance showing two major points, an unchanged detection rate of early stage HCC and a reduced false referral rate (12). Regarding the former, 497 patients without suspected HCC on B-mode US were the subjects. Although the detailed procedures are not described in this paper, scanning of the whole liver under the post-vascular phase caused by microbubble accumulation may be the principal methodology to detect lesions showing hypo-enhancement or defects. Unfortunately, the detection rate of early stage HCC was not improved by adding CEUS with Sonazoid to conventional $\mathrm{B}$-mode US (difference, $0.4 \% ; \mathrm{P}=0.16$ ). They raised 4 points to explain the result: (I) lower incidence of HCC than the prior estimate; (II) inherent limitations of CEUS similar to those of B-mode US caused by the participant's body habitus and acoustic shadowing by the aerated lung, ribs, and colonic interposition; (III) the presence of Kupffer cells in small welldifferentiated HCCs; and (IV) bias in the patient population (mostly HBV-related liver cirrhosis).

Their interpretations seem reasonable, and particularly, the third point may be the principal axis for their data. In general, discrimination between benign and malignant lesions by CEUS with Sonazoid depends on the enhancement pattern of the post-vascular phase, positive enhancement for the former and negative enhancement for the latter. However, there is a close relationship between the degree of microbubble accumulation and the cellular differentiation of HCC supported by quantitative analysis; some of early-stage well-differentiated HCC show positive enhancement in the post-vascular phase (13). Another issue is the changing enhancement patterns related to dedifferentiation. A unique study performed on HCCs with nodule-in-nodule appearance reported that dedifferentiation of HCC was accompanied by changes in the neovascularity prior to the reduction of microbubble accumulation in the post-vascular phase (14). Taken together, Kupffer cells may be present even in early stage or well-differentiated HCC with dedifferentiation typified by arterial vascularity; scanning in the post-vascular phase may not necessarily be effective to detect early HCC although it has the advantage of easy and stable observation unlike the arterial phase images created by the movement of dynamic microbubbles. In other words, screening for HCC lesions using post-vascular phase imaging might have potential pitfalls with the risk of missing such lesions.

At present, how should clinician follow-up hepatic lesions when they show iso-enhancement in the postvascular phase? A prospective study conducted in 87 postvascular phase iso-enhancement hepatic lesions (PIELs) on CEUS with Sonazoid reported that the cumulative HCC occurrence rates from PIEL $>14 \mathrm{~mm}$ were $23.5 \%$ at 1 year and $46.3 \%$ at 3 years (15). Cox regression analysis showed that PIEL $>14 \mathrm{~mm}$ (hazard ratio, 6.780; $\mathrm{P}=0.002$ ) and alpha-fetoprotein $>20 \mathrm{ng} / \mathrm{mL}$ (hazard ratio, 4.892; $\mathrm{P}=0.007$ ) were statistically significant factors for HCC occurrence; therefore, careful monitoring is required in such patients.

Overdiagnosis by B-mode US is unavoidable and may be due to the nature of non-contrast imaging. Using CEUS with Sonazoid as a next step, as expected, the false referral rate of HCC was significantly reduced (difference, 23.2\%; $\mathrm{P}<0.001)(12)$. In Park et al.'s cohort, 27 patients had suspected HCC on B-mode US, but CEUS diagnosed 18 of them as not having HCC, which was supported by following reference standard procedures. In the remaining 9 patients, 3 were considered as false-positive results by CEUS.

A previous study that compared the diagnostic ability of small hepatic lesions $(\leq 30 \mathrm{~mm})$ between CEUS with Sonazoid and gadolinium-ethoxybenzyl-diethylenetriamine pentaacetic acid (Gd-EOB-DTPA) enhanced MRI showed that the sensitivity, specificity, and accuracy of hepaticarterial phase hyper-enhancement for well-differentiated HCC was respectively $59.3 \%, 100 \%$, and $67.2 \%$ by US and $46.3 \%, 100 \%$, and $56.7 \%$ by MRI without significant difference. Meanwhile, the sensitivity, specificity, and accuracy of liver-specific-phase hypo-enhancement for welldifferentiated HCC was respectively $44.4 \%, 100 \%$, and $55.2 \%$ by US and $87.0 \%(\mathrm{P}<0.0001), 46.2 \%(\mathrm{P}=0.0052)$, and $79.1 \%(\mathrm{P}=0.0032)$ by MRI (16). Higher specificity may be the advantage of CEUS with Sonazoid; therefore, the current author was curious about the findings by Park et al. 
in 3/9 patients with false-positive results (12), although such overestimation may be likely in real-world practice.

Park et al. assessed how to use CEUS with Sonazoid for primary use or secondary use as an extensive test. Data on no difference in the detectability may limit the primary use value. Of course, the result depends on the characteristics of the hepatic lesions in the cohort. The substantial effects of CEUS in patients with NASH, which shows a global increase, require further investigation.

A Japanese study by Kudo et al. using Sonazoid accompanied by re-injection demonstrated that 16 additional HCCs that were not detected on B-mode US were detected by CEUS in a cohort of 292 patients under HCC surveillance (17). Another prospective study under randomized control setting (SELECTED) reported the advantage of CEUS with Sonazoid, finding a higher detectability of smaller lesions $(13.0 \pm 4.1 \mathrm{~mm})$ than using $\mathrm{B}$-mode US (16.7 $\pm 4.1 \mathrm{~mm}, \mathrm{P}=0.011)$ (18). Taken together, the practical benefit of using CEUS with Sonazoid in patients without suspicious HCCs on B-mode US may be controversial and remains to be elucidated.

There were some limitations to the study by Park et al. (12). Firstly, it was a single-arm study with no comparative cohort. Secondly, there were some biases: the subjects mainly had viral hepatitis, the US equipment was LOGIQ E9 (GE Healthcare) alone even in the multicenter study, and the subjects were East Asians whose body mass index/physical size was relatively smaller than Western subjects. Thirdly, the role of CEUS in the chronological order was not examined as the authors acknowledged.

In conclusion, it is necessary to find an ideal methodology for HCC surveillance, with an assessment of the costeffectiveness and survival benefits. CEUS with Sonazoid represents a non-invasive surveillance tool that is effective for the detection of HCC lesions, although the evidence is not sufficient to support the significance in international guidelines. Additional findings obtained from well-designed studies with large patient populations may reveal the true value of this technique.

\section{Acknowledgments}

None.

\section{Footnote}

Conflicts of Interest: The authors have no conflicts of interest to declare.

\section{References}

1. Kulik L, Ei-Serag HB. Epidemiology and management of hepatocellular carcinoma. Gastroenterology 2019;156:477-91.e1.

2. Forner A, Llovet JM, Bruix J. Hepatocellular carcinoma. Lancet 2012;379:1245-55.

3. Kanwal F, Singal AG. Surveillance for hepatocellular carcinoma: current best practice and future direction. Gastroenterology 2019;157:54-64.

4. Zhang BH, Yang BH, Tang ZY. Randomized controlled trial of screening for hepatocellular carcinoma. J Cancer Res Clin Oncol 2004;130:417-22.

5. Costentin CE, Layese R, Bourcier V, Cagnot C, Marcellin P, Guyader D, Pol S, Larrey D, De Lédinghen V, Ouzan D, Zoulim F, Roulot D, Tran A, Bronowicki JP, Zarski JP, Riachi G, Calès P, Péron JM, Alric L, Bourlière M, Mathurin P, Blanc JF, Abergel A, Serfaty L, Mallat A, Grangé JD, Attali P, Bacq Y, Wartelle C, Dao T, Thabut D, Pilette C, Silvain C, Christidis C, Nguyen-Khac E, Bernard-Chabert B, Zucman D, Di Martino V, Sutton A, Letouzé E, Imbeaud S, Zucman-Rossi J, Audureau E, Roudot-Thoraval F, Nahon P; ANRS CO12 CirVir Group. Compliance with hepatocellular carcinoma surveillance guidelines associated with increased leadtime adjusted survival of patients with compensated viral cirrhosis: a multi-center cohort study. Gastroenterology 2018;155:431-42.e10.

6. Trinchet JC, Chaffaut C, Bourcier V, Degos F, Henrion J, Fontaine H, Roulot D, Mallat A, Hillaire S, Cales P, Ollivier I, Vinel JP, Mathurin P, Bronowicki JP, Vilgrain V, N'Kontchou G, Beaugrand M, Chevret S; Groupe d'Etude et de Traitement du Carcinome Hépatocellulaire (GRETCH). Ultrasonographic surveillance of hepatocellular carcinoma in cirrhosis: a randomized trial comparing 3- and 6-month periodicities. Hepatology 2011;54:1987-97.

7. Heimbach JK, Kulik LM, Finn RS, Sirlin CB, Abecassis MM, Roberts LR, Zhu AX, Murad MH, Marrero JA. AASLD guidelines for the treatment of hepatocellular carcinoma. Hepatology 2018;67:358-80.

8. European Association for the Study of the Liver. EASL clinical practice guidelines: management of hepatocellular carcinoma. J Hepatol 2018;69:182-236.

9. Omata M, Cheng AL, Kokudo N, Kudo M, Lee JM, Jia J, Tateishi R, Han KH, Chawla YK, Shiina S, Jafri W, Payawal DA, Ohki T, Ogasawara S, Chen PJ, Lesmana CRA, Lesmana LA, Gani RA, Obi S, Dokmeci AK, Sarin SK. Asia-Pacific clinical practice guidelines on the 
management of hepatocellular carcinoma: a 2017 update. Hepatol Int 2017;11:317-70.

10. Maruyama H, Sekimoto T, Yokosuka O. Role of contrast-enhanced ultrasonography with Sonazoid for hepatocellular carcinoma: evidence from a 10-year experience. J Gastroenterol 2016;51:421-33.

11. Claudon M, Dietrich CF, Choi BI, Cosgrove DO, Kudo M, Nolsøe CP, Piscaglia F, Wilson SR, Barr RG, Chammas MC, Chaubal NG, Chen MH, Clevert DA, Correas JM, Ding H, Forsberg F, Fowlkes JB, Gibson RN, Goldberg BB, Lassau N, Leen EL, Mattrey RF, Moriyasu F, Solbiati L, Weskott HP, Xu HX; World Federation for Ultrasound in Medicine; European Federation of Societies for Ultrasound. Guidelines and good clinical practice recommendations for contrast enhanced ultrasound (CEUS) in the liver - update 2012: A WFUMB-EFSUMB initiative in cooperation with representatives of AFSUMB, AIUM, ASUM, FLAUS and ICUS. Ultrasound Med Biol 2013;39:187-210.

12. Park JH, Park MS, Lee SJ, Jeong WK, Lee JY, Park MJ, Lee SS, Han K, Nam CM, Park SH, Lee KH. Contrastenhanced US with perfluorobutane for hepatocellular carcinoma surveillance: a multicenter diagnostic trial (SCAN). Radiology 2019;292:638-46.

13. Kondo T, Maruyama H, Kiyono S, Sekimoto T, Shimada T, Takahashi M, Ogasawara S, Suzuki E, Ooka Y, Tawada A, Chiba T, Kanai F, Yokosuka O. Intensity-based assessment of microbubble-enhanced ultrasonography:

Cite this article as: Maruyama H, Shiina S. Contrast-enhanced ultrasonography: is it an ideal tool for hepatocellular carcinoma surveillance? Quant Imaging Med Surg 2019;9(9):1611-1614. doi: 10.21037/qims.2019.08.20
Phase-related diagnostic ability for cellular differentiation of hepatocellular carcinoma. Ultrasound Med Biol 2015;41:3079-87.

14. Maruyama H, Takahashi M, Ishibashi $H$, Okabe S, Yoshikawa M, Yokosuka O. Changes in tumor vascularity precede microbubble contrast accumulation deficit in the process of dedifferentiation of hepatocellular carcinoma. Eur J Radiol 2010;75:e102-6.

15. Kondo T, Maruyama H, Sekimoto T, Shimada T, Takahashi M, Chiba T, Kanai F, Yokosuka O, Yamaguchi T. Natural history of postvascular-phase iso-enhanced lesions on the sonogram in chronic liver diseases. J Gastroenterol Hepatol 2014;29:165-72.

16. Takahashi M, Maruyama H, Shimada T, Kamezaki H, Sekimoto T, Kanai F, Yokosuka O. Characterization of small hepatic lesions $(\leq 30 \mathrm{~mm})$ with liver-specific contrast agents: A comparison between ultrasound and magnetic resonance imaging. Eur J Radiol 2013;82:75-84.

17. Kudo M, Hatanaka K, Kumada T, Toyoda H, Tada T. Double-contrast ultrasound: A novel surveillance tool for hepatocellular carcinoma. Am J Gastroenterol 2011;106:368-70.

18. Kudo M, Ueshima K, Osaki Y, Hirooka M, Imai Y, Aso K, Numata K, Kitano M, Kumada T, Izumi N, Sumino Y, Ogawa C, Akazawa K. B-mode ultrasonography versus contrast-enhanced ultrasonography for surveillance of hepatocellular carcinoma: A prospective multicenter randomized controlled trial. Liver Cancer 2019;8:271-80. 